\section{Hypolipidemic Effects of Soybean Fermentation Broth Combined with Saponins in a Syrian Golden Hamster Model of Hyperlipidemia}

\author{
Chin-Yuh Yang ${ }^{1}$, Ming-Chi Shih ${ }^{2}$ and Yuh-Ling Lin ${ }^{3^{*}}$ \\ ${ }^{1}$ Department of Dentistry, Cheng-Hsin General Hospital, Taipei, Taiwan \\ ${ }^{2}$ Sagittarius Life Science Corporations, Taipei, Taiwan \\ ${ }^{3}$ School of Medicine, Fu-Jen Catholic University, Taipei, Taiwan
}

*Corresponding author: Yuh-Ling Lin, School of Medicine, Fu-Jen Catholic University, 510 Chung Cheng Rd, Hsin-Chuang, Taipei Hsien-24205, Taiwan, Tel: 091-9426085328; E-mail: 054230@mail.fju.edu.tw

Received date: July 3, 2017; Accepted date: July 13, 2017; Published date: July 20, 2017

Copyright: (c) 2017 Yang CY, et al. This is an open-access article distributed under the terms of the Creative Commons Attribution License, which permits unrestricted use, distribution, and reproduction in any medium, provided the original author and source are credited.

\begin{abstract}
The aim of this study was to verify the beneficial hypolipidemic effect of commercial soya bean fermentation broth with saponins (SFBS) in hamsters with hyperlipidemia induced by $0.2 \%$ cholesterol (high-fat [HF] diet). Male Golden Syrian hamsters were randomly divided into two groups: control (standard diet, $n=8$ ) and experimental (HF diet, $\mathrm{n}=32$ ). After one-week acclimatization, all animals in the experimental group fed with the HF diet for 8 weeks. The 32 hyperlipidemic hamsters were divided into four groups ( $\mathrm{n}=8$ per group), and with $3 \mathrm{mg} /$ day $/ \mathrm{kg}$ ezetimibe or 350 $\mathrm{mg} / \mathrm{kg} /$ day (SAP350) or $700 \mathrm{mg} / \mathrm{kg} /$ day (SAP700) SFBS by oral gavage over the 8 weeks or HF diet only. After 8 weeks, the SFBS significantly decreased serum total cholesterol and low-density lipoprotein cholesterol concentrations by about $20 \%$ (SAP350) and $42 \%$ (SAP700), respectively, compared with the HF diet without SFBS or with ezetimibe ( $3 \mathrm{mg} / \mathrm{kg} / \mathrm{day}$ ). We propose that the SFBS might be reducing the serum cholesterol level by increasing fecal excretion of cholesterol and bile acids by about $20 \%$ and $35 \%$, respectively. The results of biochemical analysis of kidney and liver function in the experimental animals suggested that there were no side effects of SFBS feeding for 8 weeks.
\end{abstract}

Keywords: Cholesterol; Fecal bile acid; Low density lipoprotein; Soybean fermentation broth

\section{Introduction}

Chinese traditional medicine considers that foods and medicine have the same functions of maintaining human health. Nutraceutics is an area of pharmacology concerning food components or active ingredients that might use as therapeutic agents, many of which have been reported to have biological functions including immunostimulatory, hypocholesterolemic, anticarcinogenic, antiinflammatory, antimicrobial, antiprotozoan, and molluscicidal effects and to have antioxidant properties [1]. For example, the hypocholesterolemic activity of soy protein well established that the U.S. Food and Drug Administration have approved a claim that it reduces coronary heart disease risk [2]. As Lucas et al., [3] pointed out, commercial soy protein typically contains high levels of saponins, isoflavones and other phytochemicals that may in them influence cholesterol metabolism [4,5]. Saponins are naturally occurring structurally and functionally diverse phytochemicals that are widely distributed in plants. They are a complex and chemically varied group of compounds consisting of triterpenoid or steroidal aglycones linked to oligosaccharide moieties. Different nutraceuticals may have different mechanisms of action: inhibition of cholesterol synthesis primarily through action on the enzyme 3-hydroxy-3-methylglutarylcoenzyme A (HMG-CoA) reductase, increase in low-density lipoprotein (LDL) receptor activity, reduction of intestinal cholesterol absorption, and also the ability to interfere with bile metabolism [5].

In this study, a hamster model of hyperlipidemia that has many similarities to human fat-induced atherosclerotic disease used to evaluate the hypolipidemic effect of commercial soybean fermentation broth with saponins (SFBS). Hamsters, like humans, possess cholesterol ester transfer protein and have all of the same enzymatic pathways of lipoprotein and bile metabolism, and atherosclerotic plaques similar to those in humans develop in lesion-prone areas in response to a high-fat (HF) diet [6,7].

\section{Materials and Methods}

\section{Preparation of SFBS}

SFBS (SAPONISETM), a concentrated solution of fermented soybean extract, was provided by Sagittarius Life Science Co., Ltd. Defatted soybean powder was used as the fermentation substrate. The microorganisms used in the fermentation process included Bifidobacterium, Streptococcus, Lactobacillus, and Saccharomyces, four species that often found in the human intestinal tract or in traditional fermented products. The final products were subjected to a sterilization process to ensure that they did not carry any food-borne pathogens. The crude protein, sodium, and carbohydrate content of the SFBS were $2.3 \%, 0.13 \%$, and $20.1 \%$, respectively. Some active compounds of SFBS were quantitated, including isoflavones $(40 \mu \mathrm{g} /$ $\mathrm{mL})$, soy saponins $(8 \mu \mathrm{g} / \mathrm{mL})$ and butyric acid $(6.24 \mu \mathrm{g} / \mathrm{mL})$.

\section{Animals}

Specific-pathogen-free male Golden Syrian hamsters (four weeks old) were purchased from the National Laboratory Animal Center, Taipei City, Taiwan. Animals were housed in the animal facility at $\mathrm{Fu}-$ Jen Catholic University at room temperature $\left(22 \pm 1^{\circ} \mathrm{C}\right)$ and $50 \%$ to $60 \%$ relative humidity, with a $12 \mathrm{~h}$ light-dark cycle (light on 7:00 AM). 
Distilled water and standard laboratory chow diet (AIN-93G, D10012G; Research Diets, New Brunswick, NJ, USA) were provided ad libitum. Before the experiments, the hamsters were acclimatized for 1 week to the environment and diet. At the initiation of the experiment, hamsters were randomly assign to 1 of 5 treatment diets $(n=8)$ for 8 weeks: (1) normal diet (Norm, AIN, D10012G); (2) HF diet (HF, AIN 93G modified version with $31 \% \mathrm{kcal}$ fat and $0.2 \%$ cholesterol); (3) HF diet supplemented with SFBS $350 \mathrm{mg} / \mathrm{kg} /$ day (SAP350); (4) HF diet supplemented with SFBS $700 \mathrm{mg} / \mathrm{kg} /$ day (SAP700); (5) HF diet supplemented with $3 \mathrm{mg} / \mathrm{kg} /$ day ezetimibe Ez3 [8,9]. All experimental hamsters were euthanized by $95 \% \mathrm{CO}_{2}$ asphyxiation, and blood was collected immediately.

\section{Clinical biochemical profiles}

At the initiation (0 week), and in the fourth and eighth week of the experimental period, fasting plasma was collected by centrifugation and the clinical biochemical variables including total cholesterol (TC), triglycerides (TG), lipoprotein cholesterol levels, aspartate aminotransferase (AST), alanine aminotransferase (ALT), gamma glutamyltransferase (GGT), blood urea nitrogen (BUN), and creatinine (CRE) were measured with an autoanalyzer (Dri-Chem 4000i, Fujifilm, Tokyo, Japan). The level of LDL was measured with a Toshiba tba-120tr analyzer (Toshiba Medical Systems; Tustin, CA, USA).

\section{Measurement of fecal bile acid and cholesterol excretion}

A modified version of the method reported by Modica et al., [10] was used to measure the fecal bile acid and cholesterol content. Briefly, $0.2 \mathrm{~g}$ of dried feces was mixed with $2 \mathrm{~mL}$ of $2 \mathrm{mg} / \mathrm{mL}$ sodium borohydrate in ethanol and incubated at room temperature for $1 \mathrm{~h}$. Hydrochloric acid and sodium hydroxide were added and samples were vortexed and allowed to digest for $12 \mathrm{~h}$ under reflux. The samples were then filtered and dried under nitrogen. Samples were resuspended in water and filtered through Sep-Pak C18 cartridges (Waters; MA, USA), washed and eluted with methanol and dried under nitrogen. Samples were redissolved in $1 \mathrm{~mL}$ methanol and bile acid concentrations were measured enzymatically using the Total Bile Acids Assay kit from Diazyme Laboratories (Poway, CA, USA). Fecal cholesterol was extracted as previously described [10], and the level was measured using a colorimetric Infinity cholesterol assay kit (Thermo Fisher Scientific).

\section{Statistical analysis}

All data are expressed as mean \pm standard deviation (SD). Statistical differences were analyzed by one-tailed t-test or one-way analysis of variance (ANOVA), using IBM SPSS Statistics for Windows, Version 20.0 (IBM Corp., Armonk, NY, USA) to detect significant differences between groups. Treatment differences were considered significant at $\mathrm{p}<0.05$ and very significant at $\mathrm{p}<0.01$.

\section{Ethics statement}

The Institutional Animal Care and Use Committee (IACUC) of FuJen Catholic University (FJCU) approved all animal experimental protocols (Approval Number A10411). All procedures performed on animals were in strict accordance with the Guide for the Care and Use of Laboratory Animals (Institute of Laboratory Animal Resources, Commission on Life Sciences, National Research Council). All efforts were made to improve animal welfare and minimize suffering.

\section{Results}

\section{Body weight and daily food intake}

The results shown in Table 1 indicate that the body weight of experimental animals was stable and steadily increased over the experimental period. There were no significant differences in the body weights or average food intake of the different experimental groups at 0,4 , or 8 weeks. Therefore, the HF diet and SFBS supplementation (SAP350 and SAP700 groups) did not affect body weight.

\begin{tabular}{|l|l|l|l|l|}
\hline Groups & $\mathbf{0}$ Week & 4th Week & 8th Week & Food Intake (g/day) \\
\hline Norm & $97.0 \pm 5.3$ & $110.4 \pm 8.0$ & $115.4 \pm 10.6$ & $5.35 \pm 0.28$ \\
\hline HF & $99.0 \pm 9.2$ & $114.9 \pm 9.4$ & $124.0 \pm 9.2$ & $5.28 \pm 0.72$ \\
\hline SAP350 & $96.0 \pm 5.5$ & $110.7 \pm 5.2$ & $112.3 \pm 5.4$ & $5.88 \pm 0.32$ \\
\hline SAP700 & $99.2 \pm 5.4$ & $114.8 \pm 9.3$ & $115.5 \pm 12.0$ & $5.83 \pm 0.28$ \\
\hline Ez3 & $98.7 \pm 5.8$ & $117.8 \pm 10.0$ & $119.9 \pm 11.0$ & $5.30 \pm 0.56$ \\
\hline
\end{tabular}

Norm: Normal diet; HF: High cholesterol diet; SAP350: HF+SFBS 350 mg/daykg; SAP700: HF+ SFBS 700 mg/day-kg; Ez3: HF+Ezetimibe (3 mg/day-kg). The values are the means \pm S.D. $(n=8)$.

Table 1: The body weight (g) and daily food intake for experimental animals at the initial stage (0 week), 4 th and 8 th week.

\section{Effect of SFBS on serum lipid profiles}

The lipid profiles of control and HF diet groups at the end of the 8week experiment shown in Table 2 and indicate that the TG, TC, highdensity lipoprotein (HDL), and LDL levels of the HF group are significantly higher than normal diet (control) group. However, the levels of these four lipids were lower at 4 and 8 weeks in the SAP350, SAP700, and Ez3 groups, as shown in Figures 1 and 2, and serum total cholesterol (TC) and LDL-cholesterol (LDL-C) (Figures 1A and 2A) concentrations were significantly decreased. After 8 weeks, the serum TC and LDL-C concentrations in the two SFBS-treated groups (SAP350 and SAP700) were significantly decreased about $20 \%$ and $42 \%$, respectively, as compared with those in the HF group. Indeed, the effectiveness of SFBS for decreasing the cholesterol level was comparable with that of the positive control Ez3 group treated with 3 $\mathrm{mg} / \mathrm{kg} /$ day of ezetimibe.

\begin{tabular}{|l|l|l|}
\hline Lipids & Normal diet & HF diet \\
\hline TC & $147.63 \pm 30.65$ & $202.50 \pm 16.45^{* \star *}$ \\
\hline TG & $101.75 \pm 20.47$ & $148.13 \pm 33.98^{* *}$ \\
\hline HDL & $112.38 \pm 16.27$ & $172.38 \pm 33.28^{* * *}$ \\
\hline LDL & $9.25 \pm 2.05$ & $11.00 \pm 1.85^{* \star *}$ \\
\hline $\begin{array}{l}\text { Norm: Normal diet; HF: High cholesterol diet. The value was expressed as } \\
\text { mean } \pm S D(n=8) \text { hamsters per group. Significantly different at } p<0.05\left(^{*}\right), 0.01\left(^{* *}\right) \\
\text { and } 0.001\left(^{* * *}\right) \text { by t-test, one-tail. }\end{array}$ \\
\hline
\end{tabular}

Table 2: The lipids profiles $(\mathrm{mg} / \mathrm{dL})$ of sera between normal diet and HCD diet groups were compared at the 8th weeks. 
Citation: $\quad$ Yang CY, Shih MC, Lin YL (2017) Hypolipidemic Effects of Soybean Fermentation Broth Combined with Saponins in a Syrian Golden Hamster Model of Hyperlipidemia. J Exp Food Chem 3: 127. doi:10.4172/2472-0542.1000127

Page 3 of 5

\section{Evaluation of liver and kidney function}

The results shown in Table 3 indicate that the HF group had the highest levels of AST, ALT, and g-glutaryl transferase (g-GT). However, at week 8 , there were no significant differences in these parameters between the SAP350, SAP700, and Ez3 groups and the normal diet group. The kidney function of experimental animals as evaluated by the levels of BUN and CRE also did not differ significantly between any of the groups, as shown in Table 4.

\begin{tabular}{|l|l|l|l|}
\hline Group & AST (GOT) (IU/L) & ALT (GPT) (IU/L) & Y-GTP (GGT) (mg/dL) \\
\hline Norm & $50.88 \pm 8.77^{\mathrm{a}}$ & $51.19 \pm 14.69^{\mathrm{a}}$ & $11.63 \pm 2.45^{\mathrm{a}}$ \\
\hline HF & $60.88 \pm 16.96^{\mathrm{a}}$ & $81.50 \pm 34.18^{\mathrm{b}}$ & $14.38 \pm 4.75^{\mathrm{a}}$ \\
\hline SAP350 & $52.50 \pm 29.21^{\mathrm{a}}$ & $61.25 \pm 40.20^{\mathrm{a}}$ & $12.88 \pm 3.09^{\mathrm{a}}$ \\
\hline SAP700 & $54.25 \pm 18.87^{\mathrm{a}}$ & $56.38 \pm 14.21^{\mathrm{a}}$ & $11.88 \pm 3.52^{\mathrm{a}}$ \\
\hline Ez3 & $51.75 \pm 18.90^{\mathrm{a}}$ & $56.63 \pm 13.47^{\mathrm{a}}$ & $11.75 \pm 3.62^{\mathrm{a}}$ \\
\hline
\end{tabular}

Norm: Normal diet; HF: High cholesterol diet; SAP350: HF+SFBS 350 mg/daykg; SAP700: HF+SFBS 700 mg/day-kg; Ez3: HF+Ezetimibe (3 mg/day-kg). Data are mean $\pm S D, n=8$ hamsters per group. Values in the same column with different superscripts letters $(a, b)$ significantly differ at $p<0.05$ by one-way ANOVA and Duncan's multiple range tests. (AST: aspartate aminotransferase, GOT; ALT: Alanine aminotransferase, GPT; Y-GTP: Gamma Glutamyl Transpeptidase, GGT).

Table 3: Biochemical analysis of the liver functions expressed by GOT, GTP and GGT values on sera for experimental animals at the 8th week.

\begin{tabular}{|l|l|l|}
\hline Group & BUN $(\mathbf{m g} / \mathbf{d L})$ & CRE $(\mathbf{m g} / \mathbf{d L})$ \\
\hline Norm & $50.88 \pm 8.77^{\mathrm{a}}$ & $59.19 \pm 14.69^{\mathrm{a}}$ \\
\hline HF & $60.88 \pm 16.96^{\mathrm{a}}$ & $81.50 \pm 34.18^{\mathrm{a}}$ \\
\hline SAP350 & $52.50 \pm 29.21^{\mathrm{a}}$ & $61.25 \pm 40.20^{\mathrm{a}}$ \\
\hline SAP700 & $54.25 \pm 18.87^{\mathrm{a}}$ & $56.38 \pm 14.21^{\mathrm{a}}$ \\
\hline Ez3 & $51.75 \pm 18.90^{\mathrm{a}}$ & $56.63 \pm 13.47^{\mathrm{a}}$ \\
\hline
\end{tabular}

Norm: Normal diet; HF: High cholesterol diet; SAP350: HF+SFBS 350 mg/daykg; SAP700: HF+SFBS 700 mg/day-kg; Ez3: HF+Ezetimibe (3 mg/day-kg). Data are mean $\pm S D, n=8$ hamsters per group. Values in the same column with different superscripts letters $(a, b)$ significantly differ at $p<0.05$ by one-way ANOVA and Duncan's multiple range tests. (BUN: Blood Urea Nitrogen; CRE: Creatinine).

Table 4: Biochemical analysis of the kidney functions expressed by BUN and CRE values on sera for experimental animals at the 8th week.

\section{The total cholesterol and bile acid levels in fecal samples}

To confirm the metabolic pathway of cholesterol after a highcholesterol diet with or without SFBS supplementation for 8 weeks, fecal samples collected at 0,4 , and 8 weeks. The excretion in feces of cholesterol and bile acids in the SAP350, SAP700, and Ez3 groups was higher than that in the HF group, as shown in Table 5. The effects of SFBS increased excretion of cholesterol and bile acids by about $20 \%$ and 35\%, respectively, at 8 weeks in the SAP350 and SAP700 groups. The effect of SFBS in lowering serum cholesterol and promoting the excretion of cholesterol in feces was similar to that of ezetimibe (which increased excretion by $28 \%$ at week 8 , Table 5 ).

\begin{tabular}{|c|c|c|c|}
\hline \multirow{2}{*}{ Group } & \multicolumn{3}{|l|}{ Cholesterol } \\
\hline & 0 Week & 4th Week & 8th Week \\
\hline Norm & $75.04 \pm 1.41$ & $63.76 \pm 6.02$ & $57.02 \pm 0.00$ \\
\hline HF & $70.04 \pm 25.42$ & $104.54 \pm 13.44$ & $80.54 \pm 6.37$ \\
\hline SAP350 & $67.52 \pm 14.84$ & $133.05 \pm 0.00$ & $101.04 \pm 11.29$ \\
\hline SAP700 & $70.02 \pm 8.50$ & $125.53 \pm 16.25$ & $106.53 \pm 0.70^{*}$ \\
\hline Ez3 & $74.54 \pm 14.85$ & $104.54 \pm 67.20$ & $114.04 \pm 0.00^{*}$ \\
\hline \multicolumn{4}{|c|}{$\begin{array}{l}\text { Norm: Normal diet; HF: High cholesterol diet; SAP } 700 \text { : HF+SFBS } 700 \mathrm{mg} / \mathrm{day}- \\
\mathrm{kg} \text {; SAP350: HF+SFBS } 350 \mathrm{mg} / \mathrm{day}-\mathrm{kg} \text {; Ez3: HF+Ezetimibe }(3 \mathrm{mg} / \mathrm{day}-\mathrm{kg}) \text {. } \\
\text { Each value was expressed as mean } \pm \text { SD, } \mathrm{n}=8 \text { hamsters per group. } \\
\text { Significantly different at } p<0.05\left(^{*}\right) \text { by t-test, one-tail. }\end{array}$} \\
\hline
\end{tabular}

Table 5: Compared the cholesterol level $(\mu \mathrm{mol} / \mathrm{L})$ on fecal sample of HF group with other four groups at 0,4 th and 8 th week.

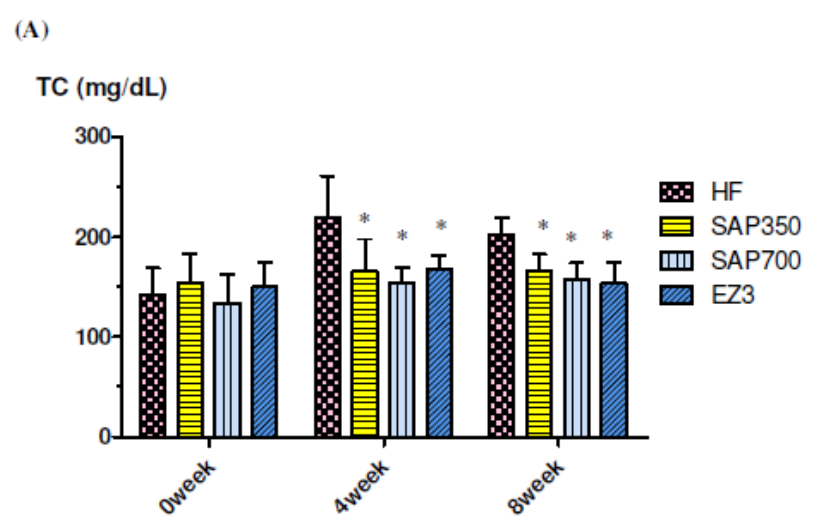

(B)

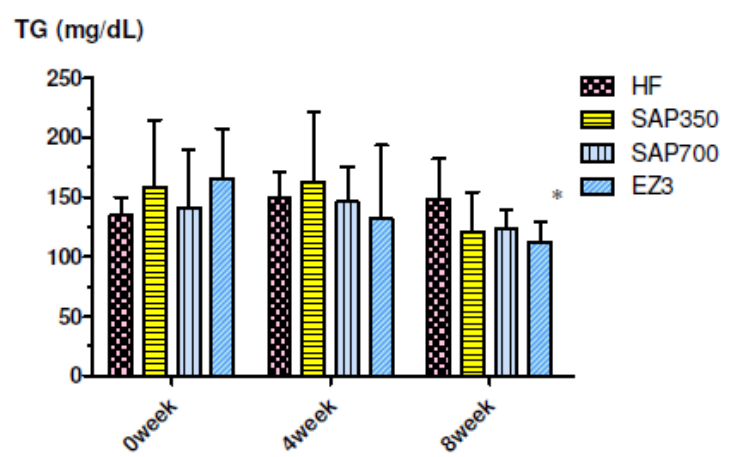

Figure 1: The sera levels of TC (A) and TG (B) of HF group were compared with other three experimental groups at $0,4^{\text {th }}$ week and $8^{\text {th }}$ week. The four experimental groups are HF: High fat diet; SAP700: HF+SFBS $700 \mathrm{mg} /$ day-kg; SAP350: HF+SFBS $350 \mathrm{mg} /$ day$\mathrm{kg}$; Ez3: HF+Ezetimibe $(3 \mathrm{mg} /$ day-kg. Data are mean $\pm \mathrm{SD}, \mathrm{n}=8$ hamsters per group. Values are significantly differs at $\mathrm{p}<0.05$ by one-way ANOVA and Duncan's multiple range tests. 


\section{Discussion}

In this study, the SFBS-supplemented groups (SAP350 and SAP700) have clearly and significantly, decreased serum TC concentration compared with the HF group (Figure $1 \mathrm{~A}$ and $\mathrm{B}$ ). This indicates that the major effect of SFBS is to lower the TC level with a minor effect on TG levels.

Saponin compounds been reported to have many pharmacological properties including anti-inflammatory, immunostimulant, hypocholesterolemic, hypoglycemic, antifungal, and cytotoxic activities [11]. The results shown in Figure 2A indicate that the two SAP groups effectively decreased the serum LDL level similar to that achieved by the positive control ( $3 \mathrm{mg} / \mathrm{kg} /$ day ezetimibe) after 4 and 8 weeks of treatment. The positive control compound ezetimibe used in this study has been shown to inhibit intestinal cholesterol absorption in both mice and human [12] via inhibition of the Niemann-Pick C1 Like 1 transporter [13]. As previously reported [12] ezetimibe monotherapy lowers plasma LDL-C concentrations by approximately $15-20 \%$, which is similar to the results of our study shown in Figure 2A.

(A)

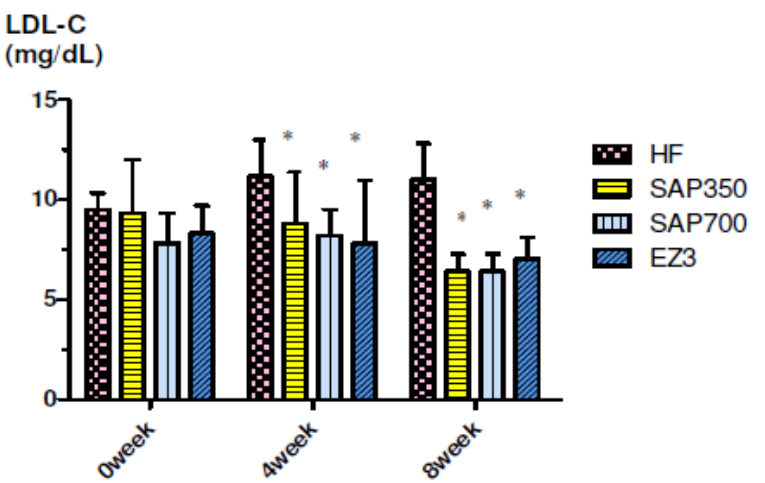

(B)

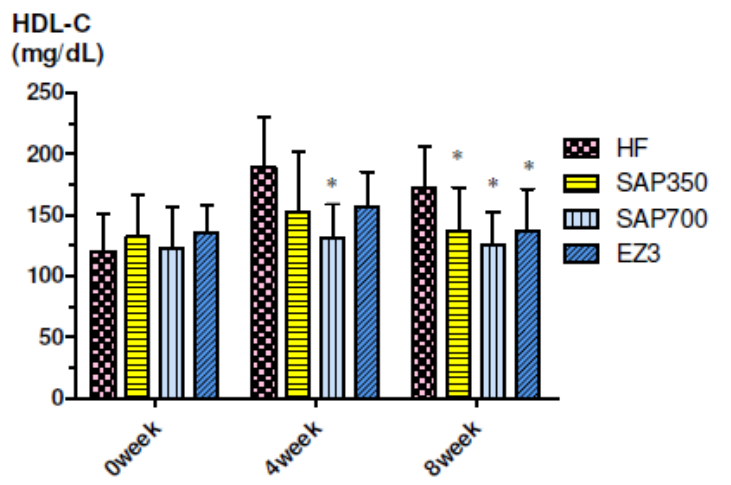

Figure 2: The sera levels of LDL (A) and HDL (B) of HF group were compared with other three experimental groups at $0,4^{\text {th }}$ week and $8^{\text {th }}$ week. The four experimental groups are HF: High fat diet; SAP700: HF+SFBS $700 \mathrm{mg} /$ day-kg; SAP350: HF+SFBS $350 \mathrm{mg} /$ day$\mathrm{kg}$; Ez3: HF+Ezetimibe $(3 \mathrm{mg} /$ day-kg. Data are mean $\pm \mathrm{SD}, \mathrm{n}=8$ hamsters per group. Values are significantly differs at $p<0.05$ by one-way ANOVA and Duncan's multiple range tests.
The results shown in Figure 2B suggest that SFBS also decreased the serum level of HDL, which could be of concern. Previous theories about the relationship between cholesterol and health have meant that research has mainly focused on therapies that raise HDL-cholesterol (HDL-C) $[14,15]$. However, recent studies aimed at increasing plasma HDL-C concentrations have not substantiated a significant reduction in cardiovascular disease risk [16,17], despite the strong inverse relationship between plasma HDL-C concentrations and cardiovascular disease risk seen in epidemiological studies $[18,19]$. Other reports have shown that the plasma levels of HDL-C do not determine the biliary or fecal excretion of cholesterol in mice [20-23], and Jakulj et al. [23] recently claimed that direct transintestinal excretion of plasma-derived cholesterol contributed substantially to fecal neutral sterol excretion in mice. However, in humans, fecal cholesterol elimination via the reverse cholesterol transport pathway considered restricted to excretion via the hepatobiliary route [23]. The lowering effects of SFBS on HDL-C serum level, explained as a normal physiological response to the decrease in LDL-C. In conclusion, the serum concentration of LDL but not HDL-C related to cardiovascular risk, and, as previously noted, the saponin components of SFBS might play an important role in lowering the serum cholesterol level.

\section{References}

1. Moses T, Papadopoulou KK, Osbourn A (2014) Metabolic and functional diversity of saponins, biosynthetic intermediates and semi-synthetic derivatives. Crit Rev Biochem Mol Biol 49: 439-462.

2. U.S. Food and Drug Administration (1999) Food Labeling Health Claims; Protein and Coronary Heart Disease; Final Rule. Federal Register 64, FR 57 October 26. U.S. Food and Drug Administration, Washington, DC.

3. Lucas EA, Khalil DA, Daggy BP, Arjmandi BH (2001) Ethanol-extracted soy protein isolate does not modulate serum cholesterol in golden Syrian hamsters: a model of postmenopausal hypercholesterolemia. J Nutr 131: 211-214.

4. Fenwick DE, Oakenfull D (1981) Saponin content of soya beans and some commercial soya bean products. J Sci Food Agric 32: 273-278.

5. Anderson RL, Wolf WJ (1995) Compositional changes in trypsin inhibition, phytic acid, saponins and isoflavones related to soybean processing. J Nutr 125: 581S-588S.

6. Barbagallo CM, Cefalù AB, Noto D, Averna MR (2015) Role of nutraceuticals in hypolipidemic therapy. Front Cardiovasc Med 11: 2-22.

7. Sima A, Bulla A, Simionescu N (1990) Experimental obstructive coronary atherosclerosis in the hyperlipidemic hamster. J Submicrosc Cytol Pathol 22: 1-16.

8. Sullivan MP, Cerda JJ, Robbins FL, Burgin CW (1993) The gerbil, hamster, and guinea pig as rodent models for hyperlipidemia. Lab Anim Sci 43: 575-578.

9. van Heek M, Austin TM, Farley C, Cook JA, Tetzloff GG, et al. (2001) Ezetimibe, a potent cholesterol absorption inhibitor, normalizes combined dyslipidemia in obese hyperinsulinemic hamsters. Diabetes 50: 1330-1335.

10. Modica S, Murzilli S, Moschett A (2011) Characterizing bile acid and lipid metabolism in the liver and gastro-intestinal tract of mice. Curr Protoco Mouse Biol 1: 289-321.

11. Marrelli M, Conforti F, Araniti F, Statti GA (2016) Effects of saponins on lipid metabolism: a review of potential health benefits in the treatment of obesity. Molecules 21: 1404.

12. Sudhop T, Lütjohann D, Kodal A, Igel M, Tribble DL, et al. (2002) Inhibition of intestinal cholesterol absorption by ezetimibe in humans. Circulation 106: 1943-1948.

13. Davis HR, Zhu LJ, Hoos LM, Tetzloff G, Maguire M, et al. (2004) Niemann-Pick C1 Like 1 (NPC1L1) is the intestinal phytosterol and cholesterol transporter and a key modulator of whole-body cholesterol homeostasis. J Biol Chem 279: 33586-33592. 
Citation: Yang CY, Shih MC, Lin YL (2017) Hypolipidemic Effects of Soybean Fermentation Broth Combined with Saponins in a Syrian Golden Hamster Model of Hyperlipidemia. J Exp Food Chem 3: 127. doi:10.4172/2472-0542.1000127

Page 5 of 5

14. Wright RS (2013) Recent clinical trials evaluating benefit of drug therapy for modification of HDL cholesterol. Cur Opin Cardiol 28: 389-398.

15. Bosch N, Frishman WH (2014) Newer therapeutic strategies to alter HDL level and function. Cardiol Rev 22: 17-24.

16. Briel M, Ferreira-Gonzalez I, You JJ, Akl EA, Wu P, et al. (2009) Association between change in high density lipoprotein cholesterol and cardiovascular disease morbidity and mortality: systematic review and meta-regression analysis. BMJ 338: b92.

17. Boden WE, Probstfield JL, Anderson T, Chaitman BR, DesvignesNickens P, et al. (2011) Niacin in patients with low HDL cholesterol levels receiving intensive statin therapy. New Engl J Med 365: 2255-2267.

18. deGoma EM, DeGoma RL, Rader DJ (2008) Beyond high-density lipoprotein cholesterol levels evaluating high-density lipoprotein function as influenced by novel therapeutic approaches. J Am Coll Cardiol 51: 2199-2211.
19. Barter PJ, Caulfield M, Eriksson M, Grundy SM, Kastelein JJP, et al. (2007) Effects of torcetrapib in patients at high risk for coronary events. New Engl. J Med 357: 2109-2122.

20. Groen AK, Bloks VW, Bandsma RH, Ottenhoff R, Chimini G, et al. (2001) Hepatobiliary cholesterol transport is not impaired in Abca1-null mice lacking HDL. J Clin Invest 108: 843-850.

21. Jolley CD, Woollett LA, Turley SD, Dietschy JM (1998) Centripetal cholesterol flux to the liver is dictated by events in the peripheral organs and not by the plasma high density lipoprotein or apolipoprotein A-I concentration. J Lipid Res 39: 2143-2149.

22. Xie C, Turley SD, Dietschy JM (2009) ABCA1 plays no role in the centripetal movement of cholesterol from peripheral tissues to the liver and intestine in the mouse. J Lipid Res 50: 1316-1329.

23. Jakulj L, Besseling J, Stroes ESG, Groen AK (2013) Intestinal cholesterol secretion: future clinical implications. Neth J Med 71: 459-465. 